Research Article

\title{
Regional comparative analysis of factors that may delay child-birth for at least 10 months among women in Ghana after marriage.
}

\author{
Abdul-Karim Iddrisu ${ }^{\mathrm{a}}$, Mustapha Adams ${ }^{\mathrm{b}}$, Akuye-Shika Odametey ${ }^{\mathrm{a}}$, Nana Kofi Mensah ${ }^{\mathrm{c}}$, Paul A. \\ Kwotuah $^{\mathrm{d}}$ \\ ${ }^{a}$ University of Energy and Natural Resources, School of Sciences, Department of Mathematics and Statistics, \\ Ghana, ${ }^{b}$ University of Cape Coast, College of Agriculture and Natural Sciences, School of Physical Sciencs, \\ Department of Statistics, Ghana, ${ }^{c}$ Kumasi Technical University, Department of Mathematics and Statistics, \\ Ghana, and ${ }^{d}$ Zoomlion Ghana Limited.
}

\begin{tabular}{l} 
A R TICLE I N F O \\
\hline Article history: \\
Received xx January 2019 \\
Received in revised form 00 \\
January 00 \\
Accepted 00 February 00
\end{tabular}

Keywords:

Akaike Information Criterion; Bayesian InformationCriterion; ChiSquare test statistic; logistic regression; Ghana Demographic and Health Survey; predictors; Sensitivity; specificity; Receiver Operating Characteristic curve; risk factors.

\section{Introduction}

\section{ABSTRACT}

Introduction: Infertility or difficulty related to conception and childbirth is still a global health concern including Ghana. Infertility or child-birth associated difficulties after marriage can lead to divorce. However, risk factors associated with child-birth difficulties are often difficult to detect by both the Gynaecologist and the couple involved. This makes proposing solutions to issues related to child-birth usually unsuccessful.

Methods: This study seeks to identify risk factors associated with child-birth among married women in Ghana. This was achieved by using a logistic regression model for the dichotomous birth length (birth within 10 months or after 10 months in marriage) variable, adjusting for risk factors of birth length. The data used for the study were obtained from the 2014 Ghana Demographic and Health Survey, consisting of 5,004 complete cases. Statistical analyses were carried out using STATA version 14.1, best-fitting model selected from candidate models using their respective Akaike Information Criterion or Bayesian Information Criterion and the predictive power of such model determined using the Receiver Operating Characteristic curve.

Results: Respondents with Akan ethnic background are less likely to deliver their first child after 10 months of marriage, wives who reported that beating is justified if she goes out without her husband's notice are more likely to give birth to their first child after 10 months of marriage, wives who reported that beating is justified when she burns food are less likely to give birth to their first child after 10 months of marriage. A unit increase in the age of respondent at first sex at first cohabitation decreases the likelihood of giving birth to the first child after 10 months in marriage. Rich and middle-class wives are more likely to give birth after 10 months in marriage.

Discussion and Conclusions: For wives to conceive within 10 months of marriage, wives and husbands should or are encouraged to have frequent sex, any negative social behavior or policies must be discouraged. Husbands should openly express their desire and love for their children since this increases the likelihood of wives desire to give birth. This leads to frequent sex, which then reduces conception time, and hence, child-birth within the shortest possible time.

* Corresponding author. Tel.: +233-507-073-29.

E-mail address: karim@aims.ac.za 
It is known that procreation or child-birth is one of the main aims of marriage, and child-birth is so crucial in marriage that it often determines the happiness of the couple. Research on improving birth rates has received much attention following success of In Vitro Fertilization (IVF) in 1979 [1]. The IVF consists of series of procedures used to help with fertility or prevent genetic problems and assists with the conception of a child. In the mid-1980s, various authors conducted research to investigate the psycho-social effects of infertility [2] and IVF treatment [3], [4]. These authors reported that infertility affects emotional well-being, satisfaction with life and self-esteem [1]. Failure of measures, such as Assisted Reproductive Technology (ART), to improve fertility is associated with reduced life satisfaction, self-confidence as well as substantial psychological distress [1].

One may hypothesize that pregnancy and parenthood experienced after infertility and assisted conception will be very appealing. However, it has been shown that past infertility and ART conception are likely to be associated with higher anxiety about pregnancy loss, delayed mother-infant attachment, reduced maternal confidence, hypervigilant and overprotective parenting and idealized expectations of parenting capacity and the infant [1]. Clinical reports supported with qualitative studies indicated that pregnancy and parenting may be more complex psychologically after assisted than spontaneous conception [5], [6]. For methods to improve chances of conception and child-birth, others resort to rituals such as prayers, charms, amulets [7].

The implication is that too much delay in child-birth after marriage or when it is likely that one cannot give birth after marriage can lead to divorce [8]. However, causes of delay in child-birth are often difficult to detect by both the Gynaecologist and the couple involved, making treatment unsuccessful. What makes delay in child-birth after marriage even more problematic is the difficulty associated with efforts to detect/determine the cause of such delay. Most often, couples tend to blame each other. In most cases, even the Gynaecologist is required to use various methods to identify the cause of delay in child-birth with various approaches/solutions to address the issues identified to be related to the delay 
in child-birth. Some of the causes (such as social factors) of delay in child-birth cannot be detected by any Gynaecological examination. It may be much easier to detect and propose solutions to issues that can be detected through medical examination. However, for social factors/causes, it may be very difficult to detect because only the couple involved know that such factors exist in their marriage. The worse of this is that, the couple may not report such factors to a Gynaecologist if they are not asked directly by the Gynaecologist. Most often, society rarely considers social factors as potential causes of delay in child-birth.

Hammarberg and colleagues [1] study reviewed the available evidence of the psychological and social consequences of pregnancy, childbirth and early parenting after assisted conception systematically. Various authors [9]-[11] revealed that there is a positive association between women's empowerment and some aspects of their health, such as fertility and contraception. Prata and colleagues [11] research provided evidence of the relationship between women's empowerment and pregnancy or child-birth, including abortion. A research conducted in Northern China revealed a significant association between women's infertility incidence with their BMI, state of exercise, amount of menstrual flow, number of pregnancies and number of abortions and among men, both staying up late and engaging in hightemperature occupations are independent factors affecting their fertility [12]. Rakesh and colleagues [13] revealed that lifestyle factors, such as the age at which to start a family, nutrition, weight, exercise, psychological stress, environmental, and occupational exposures, are associated with fertility. Lifestyle factors such as cigarette smoking, illicit drug use, and alcohol and caffeine consumption can negatively influence fertility [13].

In Ghana, increase in the level of contraceptive use is one of the main causes of reduced fertility [14]. Other factors affecting fertility indirectly include age of woman, education, religion, place of residence and child mortality experience. There is inadequate and affordable high quality infertility services in 
[8]. Hence, most women seek to improve their fertility by resorting to methods such as traditional healing, witchcraft and spiritual mediation [8]. Severe sociocultural and economic challenges increase the rate of infertility among women in Ghana and hence, there is the need for accessible and affordable high quality infertility care in Ghana [8].

In this paper, we explored the effects of socio-cultural and socio-economic factors that are likely to influence conception time among women after marriage in Ghana. Hence, we structured the paper into four main sections as follows. We have already given the background of the study in Section 1 . We introduce the study setting, size and source of data, and statistical methodologies used in Section 2.Section 3 presents the results of the statistical analyses using the data. We discussed the results and gave concluding remarks in Section 4.

\section{Material and Methods}

In this section, we introduced the study setting and the source of data. We also introduced the outcome variable of interest in this study, as well as factors that determine the value or the status of this outcome variable. Finally, we discussed statistical approaches used in this study.

\subsection{Study setting and data source}

This study is conducted in Ghana and the data used for the study are obtained from the Ghana Demographic and Health Survey for 2014. This study is a cross-sectional, where the outcome variable of interest and its associated risk factors were measured at single time point. In this study, we focused on individual birth record data, obtained from respondents during the survey. We observed that some of the individual records have missing values [15]-[18] and hence analyses were restricted to only the complete cases [18]. The complete data consist of 5,004 individuals, who provided responses of how long it takes for them to give birth to their first child after marriage. Using these data, we categorised individuals into two groups (birth length status); that is, those who gave birth to their first child within 10 months after marriage and those who gave birth after 10 months of marriage. Also, we consider 
data on some selected risk factors conception. Ethical approval and consent to participate statements can be found on http://dhsprogram.com/What-We-Do/Protecting-the-Privacy-of-DHS-SurveyRespondents.cfm, approved by the ICF International Institutional Review Board (IRB). We will now introduce the outcome variable and the risk factors of birth length status

\subsection{Outcome variable}

In this study, the outcome variable of interest is a dichotomous birth length status (which takes the value of 0 if an individual gives birth to first child within 10 months of marriage or 1 if after 10 months of marriage). A descriptive statistics of this variable is presented in Table 1.

\subsection{The risk factors}

The status of the outcome variable, introduced in the previous section, depends on certain risk factors. These risk factors predict the status of the outcome variable. In this section, we introduce the risk factors for the outcome variable. These risk factors will be used in the data analyses section to account for their influence on the status of the outcome variable.

The study accounted for the effect of partner's educational attainment on birth length status (which takes a value of 0 if no education, 1 if primary education, 2 if secondary, and 3 if higher education). We also adjusted for the effect of pregnancy termination on birth lengthstatus, where respondent was asked if she ever terminated pregnancy (which takes a value of 0 if no and 1 if yes). Other risk factors are: residential status (takes a value of 0 if an individual live in a rural area or 1 if an individual live in urban area), ever used contraceptive (takes a value of 0 if no or 1 if yes), anaemia status (takes a value of 0 if no anaemia or 1 if yes), beating justified if refuses to have sex, if burns food, argues with husband, neglects child, or goes out without informing husband (each takes a value of 0 if no or 1 if yes). We also adjusted for the effects of knowledge on ovulation (takes a value of 0 if no or 1 if yes), religion (takes a value of 0 if no religion, 1 if Islamic religion, or 2 if Christian religion), ethnicity (takes a value of 0 if akan, 1 if Mole-Dagbani, or 2 if others), and husband having more than 1 wife 
(takes a value of 0 if no or 1 if yes). The study also assessed for regional effect birth lengthstatus. We also adjust for the effect of some continuous risk factors such as age at marriage, haemoglobin level, and weight, body mass index (BMI) and age at first sex at first cohabition.

Table 1 presents descriptive statistics of the variables used (outcome and risk factors) in this study. It can be observed that high proportion $(76 \%)$ of the respondents give birth to their first child beyond 10 months after marriage, with approximately $61 \%$ of the respondents living in rural areas. Only $21 \%$ of the respondents have ever terminated pregnancy and (approximately 49\%) of these respondents use oral contraceptives. The descriptive statistics also suggest that approximately $22 \%$ of the respondents have anaemia and majority $(84 \%)$ of the respondents' husbands do not have more than one wife. We observed that majority (approximately 41\%) of the respondents have secondary education followed by no education (with 39\%), and only $8 \%$ have higher education. Respondents were also asked whether beating of wife is justified in situations such as going out without husband's notice, neglect of a child, arguing with the husband, refusal to have sex with the husband, and burning of food. From the descriptive statistics, majority $(78 \%, 72 \%, 78 \%, 71 \%$, and $89 \%$ respectively) of the respondents (in each situation) reported that beating is not justified. Majority (89\%) of the respondents are poor, with $58 \%$ are Christians and $21 \%$ are Moslems. Approximately 52\% of the respondents have no knowledge about their ovulation cycle, where 35\% have Akan ethnic background and 29\% have Mole-Dagbani ethnic background. The mean weight, haemoglobin level, age at marriage, and age at first sex at first cohabition are 612, 120,30, and 19 respectively. Majority (approximately 17\%) live in the Northern Region and minority in the Greater Accra and Volta Regions.

Table 1: Descriptive statistics of the outcome variable and the predictors

Variable $n(\%$ or mean)


1-10 months

$1,201(24.00)$

$>10$ months

3,803 (76.00)

\section{Residential status}

Rural

$3,055(61.05)$

Urban

1,949 (38.95)

Ever terminated pregnancy

No

3,945 (78.84)

Yes

1,059 (21.16)

Ever used contraceptive

No

$2,467(49.30)$

Yes

$2,537(50.70)$

Anemia

No

3,921 (78.36)

Yes

1,083 (21.64)

Husband has at least one wife

No

$4,181(83.55)$

Yes

$823(16.45)$

Partner's educational level

No education

$1,943(38.83)$

Primary

583 (11.65)

Secondary

$2,078(41.53)$

Higher

400 (7.99)

Beating justify if wife goes out without husband's notice?

No

$3,892(77.78)$

Yes

$1,112(22.22)$

Beating justify if wife neglects child?

No

3,604 (72.02)

Yes

$1,400(27,98)$ 
Beating justify if wife argues with husband?

No

3,878 (77.50)

Yes

$1,126(22.50)$

Beating justify if wife refuses to have sex with husband?

No

4,056 (81.06)

Yes

984 (18.94)

Wealth index

Poor

3,493 (69.80)

Middle income 911 (18.21)

Higher income $600(12.00)$

Beating justify if wife burns food?

No

4,453 (88.99)

Yes

551 (11.01)

\section{Religion}

None

$1,048(20.94)$

Islamic religion

1,067 (21.32)

Christianity

2,889 (57.73)

Ethnicity

Others

1,776 (35.49)

Akan

1,819 (36.35)

Mole-Dagbani

1,409 (28.16)

Knowledge of ovulation

No

2,597 (51.90)

Yes

2,407 (48.10)

\section{Region}

Ashanti

500 (9.99)

Brong Ahafo

498 (9.95)

Central

482 (9.63)

452 (9.03) 
Eastern

$368(7.35)$

Greater Accra

$822(16.43)$

Northern

$504(10.03)$

Upper East

$472(9.43)$

Upper West

$389(7.77)$

Volta

$517(10.33)$

Western

Mean age of respondent

$2,520(30.68)$

Mean age at first sex of first cohabition

$2,520(19.00)$

Mean weight

$2,520(612.42)$

Mean of haemoglobin level

$2,520(119.65)$

\subsection{Statistical analysis}

In this section, we discussed some selected statistical approaches/tools that allowed us to investigate the relationship between the outcome variable and the predictors of the status of the outcome. In this study, we used the logistic regression model [19], [20], [29]-[31], [21]-[28] to establish the relationship and to estimate the effect of the predictor variables on birth length status. The general form of a logistic regression model can be written as

$$
\operatorname{logit}\left[\operatorname{Pr}\left(y_{i} \mid \mathbf{X}, \boldsymbol{\beta}\right)\right]=\operatorname{logit}(p)=\log \left(\frac{p}{1-p}\right)=\beta_{0}+\beta_{1} X_{1}+\cdots+\beta_{p} X_{p}
$$

where $\mathrm{X}_{1}, \cdots, \mathrm{X}_{\mathrm{p}}$ are the risk factors/predictors; $\beta_{0}, \cdots, \beta_{\mathrm{p}}$ are parameter estimates representing the effects of their corresponding risk factors on the dichotomous response variable (birth length status); $\mathrm{y}_{\mathrm{i}}$ is the outcome which equals 1 if respondent $i$ gives birth to her first child after 10 months of marriage and 0 if within 10 months; $\mathrm{X}$ is a design matrix for the predictors; $\beta$ is a vector of the parameter estimates. Also, $p$ is probability that a respondent gives birth after 10 months of marriage andp/(1-p) is the odds of the outcome variable among those who exposed to the predictors relative to those who are 
not exposed to the same predictors. So in effect, the $\beta$ is the $\log$ odds ratio of the birth length status for those are exposed to the predictors relative to those who are not exposed.

We use this model (1) to predict the response probability for an individual for which the values of the predictors in the model are observed. In order to determine the predicted probability, we need to backtransform using

$$
\hat{p}=\frac{\left(\hat{\beta}_{0}+\hat{\beta}_{1} X_{1}+\cdots+\hat{\beta}_{p} X_{p}\right)}{\left(1+\hat{\beta}_{0}+\hat{\beta}_{1} X_{1}+\cdots+\hat{\beta}_{p} X_{p}\right)^{\prime}}
$$

where $\widehat{\beta}_{1}, \cdots, \widehat{\beta}_{\mathrm{p}}$ are estimators of $\beta_{1}, \cdots, \beta_{\mathrm{p}}$ respectively. These predicted probabilities are used to classify individuals into either those who actually give birth to their first child within 10 months after marriage or after 10 months of marriage. This approach is known as classification [32], [33]. Thus, to assign an individual to one of two groups on the basis of the predicted response probabilities, we need to identify a "threshold" value, $\pi_{0}$ in such as way that if $\hat{p} \geq \pi_{0}$, then an individual should be classified into group 1 and if $\hat{\mathrm{p}}<\pi_{0}$, then an individual should be classified into group 2 . This means that $\pi_{0}=0.5$ if the two groups are symmetrical. Also, $\pi_{0}$ can be determined from the observed data, where $\pi_{0}$ is chosen so as to either minimize the overall proportion of misclassification or to compromise between the minimization of the 2 misclassification probabilities (that is the probability of allocating an individual to group 1 when he/she should be in group 2 and vice versa).

When our two groups refer to those who give birth to their first child within 10 months and those who give birth to their first child after 10 months of marriage, we can summarize the relationship between the true situation and the prediction as shown in Table 2. Using the information in Table 2, we defined sensitivity as the percentage of individuals who give birth after 10 months of marriage are classified as actually giving birth to their first child after 10 months of marriage. This implies that sensitivity is 
given by $\mathrm{a} /(\mathrm{a}+\mathrm{c}) \times 100$. We also define specificity as the percentage of individuals who give birth to their first child within 10 months of marriage are classified as those who do not actually give birth after 10 months of marriage (give birth with 10 months of marriage). Thus, specificity is given by $b /(b+d) \times 100[34]$. We define probabilities of the two misclassification situations as $(1) b /(b+d)=$ 1-SPEC (expressed as proportion), which represents the probability of positive prediction given that an individual gives birth to the first child within 10 months of marriage and $(2) a /(a+c)=1-\$ S E N$ (expressed as proportion), which represents the probability of negative prediction given that an individual gives birth to the first child after 10 months of marriage. These methods are often used in disease status prediction and classification, and depending on the nature of the disease, one of these misclassifications may be more serious than the other. More often, the focus is to minimize probability of false negative, which is equivalent to maximizing sensitivity.

In this study, we used the Receiver Operating Characteristic (ROC) curve [35], [36] to determine the predictive power of the model fitted to the birth records data. The ROC curve is a plot of sensitivity versus 1 -specificity as the cutoff $\pi_{0}$ varies. Since we classify an individual as give birth to first child after 10 months of marriage if $\hat{p} \geq \pi_{0}$, and within 10 months if $\hat{p}<\pi_{0}$, the number of positive predictions will increase as the threshold decreases. This gives an indication that sensitivity will increase with decreasing $\pi_{0}$ and 1-specificity will increase with decreasing $\pi_{0}$. On the other hand, when sensitivity is equal to 1 - specificity, the probability of positive prediction give that an individual gives birth to first child after 10 months is comparable to probability of positive prediction given that an individual gives birth child with 10 months. In this situation, the model has no predictive power. For a highly predictive model, we want sensitivity to be much bigger than 1-specificity (we want sensitivity to increase much faster than 1 -specificity) as $\pi_{0}$ goes from 1 to 0. Statistical analyses in this study were carried out using STATA version 14.1 software [37], [38]. 
Table 2: Prediction and classification of birth length status

\begin{tabular}{lccc}
\hline Prediction & $\begin{array}{c}\text { Birth after 10 } \\
\text { months }\end{array}$ & $\begin{array}{c}\text { Birth within 10 } \\
\text { months }\end{array}$ & $\begin{array}{c}\text { Total predictions } \\
\begin{array}{l}\text { Positive } \\
\text { prediction }\end{array}\end{array}$ \\
$\begin{array}{l}\text { TRUE +Ve (a) } \\
\text { prediction }\end{array}$ & FALSE +Ve (b) & $\begin{array}{r}\text { Number of +Ve predictions } \\
(\mathrm{a}+\mathrm{b})\end{array}$ \\
& FALSE -Ve (c) & TRUE -Ve (d) & Number of -Ve predictions \\
& After 10 months & Within 10 months & \\
TRUE totals & $(\mathrm{a}+\mathrm{c})$ & $(\mathrm{b}+\mathrm{d})$ & \\
\hline
\end{tabular}

\section{Results}

In this section, we presented and discussed the results obtained from the logistic regression model (1). In this section, we built a logistic regression model to estimate effects and to assess the significance of the predictors on the status of the outcome (birth length). We selected the best predictors/model by going by using automatic stepwise variable selection procedure in five scenariors. The STATA code for this automatic stepwise variable selection procedure is attached in Appendix I. We fitted four logistic regression models, Model A, Model B, Model C, Model D, and Model E to the birth length status variable. In the Models A, B, C, D, and E, predictors with p-values greater than 0.8, 0.6, 0.3, 0.2, and 0.05 are respectively removed. These models were then compared and best fitting model selected using their respective AICs or BICs. The model with the lowest AIC or BIC and smallest number of parameters is the best fitting model for predicting/estimating the status of birth length. The models with their respective AICs shown in Table 4. It can be observed in Table 4 that the best fitting model is the Model D since it has the lowest AIC and BIC.

We now assessed the predictive power of the Model D using the ROC curve to estimate the area under the curve. The ROC curve is a plot of sensitivity versus 1 -specificity. This means that when sensitivity 
$=1$-specificity, the area under the curve is $50 \%$, corresponding to no predictive power. If sensitivity increases faster than 1-specificity, the more bowed the ROC curve and the bigger the predictive power of the model. This corresponds to a larger area under the ROC curve. Hence the shape of the ROC curve and the area under the curve is an indication of the predictive power of the model. Hence, the ROC curve displayed in Figure 1 gives an indication that the area under the curve is approximately $61 \%$, indicating that the model has bigger predictive power.

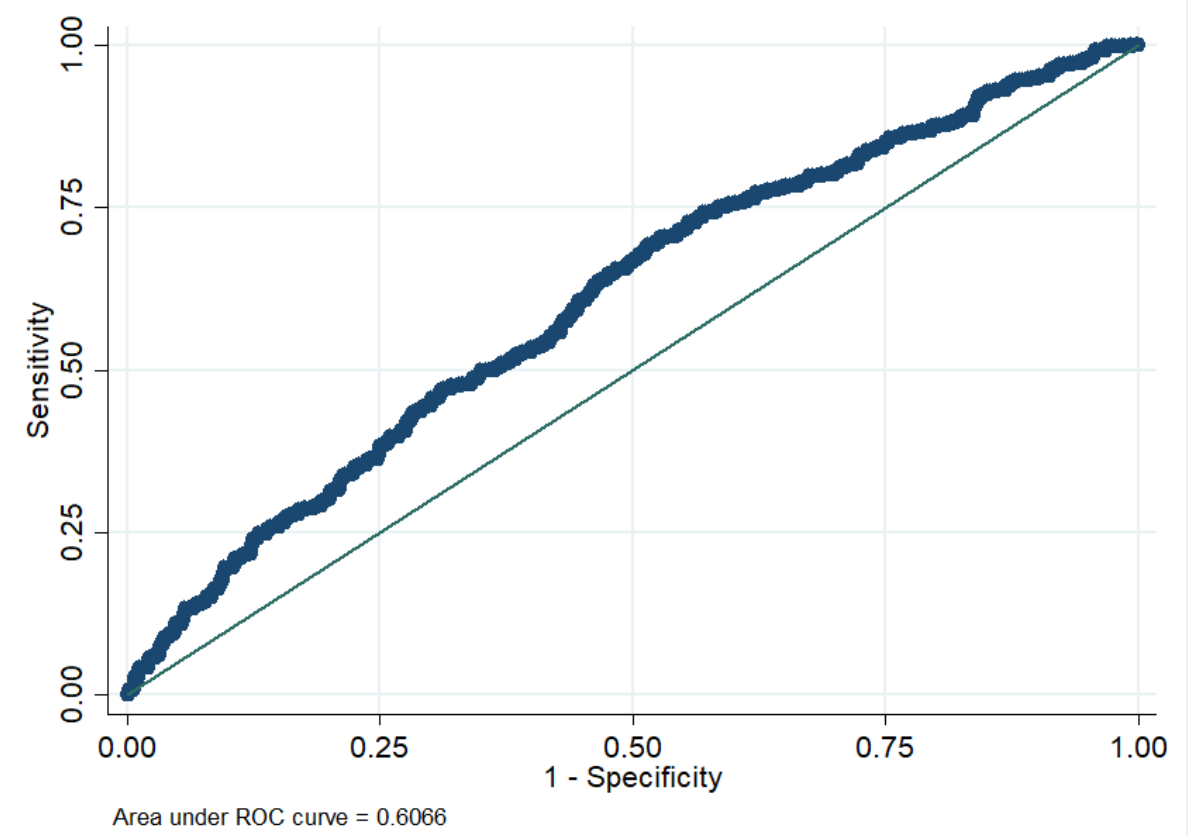

Figure 1: ROC curve as a graph of sensitivity versus 1-specificity.

The results of the best fitting Model D are presented in Table 5. Here, the unadjusted OR and adjusted OR are presented. We observed that women who reported that beating is justified if she goes out without her husband's notice are more likely $(\mathrm{OR}=1.703,95 \% \mathrm{CI}=1.193,2.432)$ to give birth to their first child after 10 months of marriage. This finding appears to suggest that wives are more likely to violate this order and hence there may be frequent misunderstanding between partners, which may 
subsequently leads to infrequent sexual intercourse which may delay conception among such women. Wives who reported that beating is justified when she burns food are less likely ( $\mathrm{OR}=0.625,95 \%$ $=0.423,0.923)$ to give birth to their first child after 10 months of marriage. These findings are statistically significant and appear to give an indication that various forms of social violence are key factors in determining how long a woman stays in a marriage before giving birth to the first child and, possibly, the next child and so on.

We found that respondents who have akan ethinic background are significantly less likely $(\mathrm{OR}=$ $0.688,95 \% \mathrm{CI}=0.546,0.865)$ to deliver their first child after 10 months of marriage relative to those who have none akan background. The results also showed that for every unit increase in the age of respondent at first sex at first cohabition, there is a decrease $(\mathrm{OR}=0.952,95 \% \mathrm{CI}=0.927,0.977)$ in the likelihood of giving birth to the first child after 10 months in marriage. This increase is significantly significant and suggests that if a woman stay longer to have her first sex, then such woman is more likely to have more sex in marriage and more likely to conceive within 1 month of marriage. Though not general, but it is more likely that younger wives and those who stays longer to have their first sex and may be more willing or have much desire to have sex, hence more likely to conceive with 1 month of the marriage. The results also showed that partners who are classified as middle and rich income class are respectively more likely $(\mathrm{OR}=1.326,95 \% \mathrm{CI}=1.001,1.760)$ and $(\mathrm{OR}=1.390,95 \% \mathrm{CI}=1.044$, 1.850) to give birth $t$ their first child 10 months after marriage.

The following variables were found to have no significant effect on the outcome variable: Partners whose have higher education are less likely $(\mathrm{OR}=-0.897,95 \% \mathrm{CI}=0.800,1.005)$ to give birth to their first child after 10 months of marriage (that is, they are more likely to give to their first child within 10 
months of marriage) compared with those who have no education. On the contrary, those with Primary education are more likely $(\mathrm{OR}=1.313,95 \% \mathrm{CI}=0.965,1.786)$ to give birth to their first child after 10 months of marriage. Wives who reported that beating is justified if she neglects child are more likely $(\mathrm{OR}=0.763,95 \% \mathrm{CI}=0.563,1.035)$ to give birth to their first child within 10 months of marriage. This finding which may suggests that wives who believe that husbands care much about their children are more willing to give first within the shortest possible time. Also, wives who reported that beating is justified when she refuses with her husband are more likely $(\mathrm{OR}=1.337,95 \%=0.953,1.875)$ to give birth to their first child after 10 months of marriage.

We found that for every unit increase in the age of respondent at marriage, there is 1.012 increase in the likelihood of giving birth to the first child after 10 months of marriage. This finding is probably due to higher proportion (28\%) of contraceptive use among older age ( $>18$ years) wives relative to approximately $26 \%$ of contraceptive use among the younger age $(\leq 18)$ age wives. Wives from Central and Volta regions are respectively less likely $\mathrm{OR}=0.761,95 \% \mathrm{CI}=0.551,1.052$ and $\mathrm{OR}=-$ $0.751,95 \% \mathrm{CI}=0.515,1.094)$ to give to their first child after 10 months of marriage relative to those in Greater Accra. Wives having knowledge about their ovulation cycle are less likely $(\mathrm{OR}=0.878$, $95 \% \mathrm{CI}=0.726,1.061)$ to give birth after 10 months of marriage. This is because such wives are able to plan and have sex at the time when conception chance is high. There is an increase $(\mathrm{OR}=1.165$, $95 \% \mathrm{CI}=0.960,1.142)$ in the likelihood of giving birth after 10 months of marriage among women who ever experienced anaemia relative to those who never experienced anaemia. Also, body mass index (bmi) increases $(\mathrm{OR}=1.00,95 \% \mathrm{CI}=0.999,1.000)$ the likelihood of giving birth after 10 months of marriage. 


\begin{tabular}{ccccc}
\hline Model & $\begin{array}{c}\text { Number of } \\
\text { observations }\end{array}$ & $\begin{array}{c}\text { degrees of } \\
\text { freedom }\end{array}$ & AIC & BIC \\
\hline A & 5,004 & 33 & 2664.608 & 2854.449 \\
B & 5,004 & 26 & 2651.69 & 2801.262 \\
C & 5,004 & 18 & 2640.934 & 2744.484 \\
D & 5,004 & 17 & 2640.12 & 2737.917 \\
E & 5,004 & 6 & 2644.962 & 2679.478 \\
\hline
\end{tabular}

Table 4: : Unadjusted and adjusted odds ratios and $95 \%$ confidence interval $(95 \% \mathrm{CI})$ : logistic regression model.

\begin{tabular}{lcc}
\hline Covariates & UaOR $(95 \% \mathrm{CI})$ & $\mathrm{aOR}(95 \% \mathrm{CI})$ \\
\hline Ethnicity & 1 (reference) & 1 (reference) \\
Others & $0.917(0.802,1.049)$ & $0.688(0.546,0.865)$ \\
Akan & & \\
Partner's educational level & 1 (reference) & 1 (reference) \\
No education & $0.853(0.793,0.918)$ & $0.8987(0.800,1.005)$ \\
Higher education & $1.066(0.869,1.308)$ & $2.313(0.965,1.786)$
\end{tabular}

Beating justifted if wife goes out without husband's notice?

No

Yes

1 (reference)

1 (reference)

$1.357(1.151,1.599) \quad 1.703(1.193,2.432)$

Beating justifted if wife neglects child?

No

$$
1 \text { (reference) }
$$

1 (reference)

Yes

$1.155(0.997,1.338)$

$0.763(0.563,1.035)$

Beating justified if wife refuses sex with husband

No

1 (reference)

1 (reference)

Yes

$1.335(1.121,1.590) \quad 1.337(0.953,1.875)$ 
Beating justifted if wife burns food?

No

Yes

Age of respondent at marriage

Age at ftrst sex at first cohabition

Region

Greater Accra

Central

Volta

\section{Knowledge of ovulution}

No

Yes

Wealth index

Poor

Middle

Rich

Has anaemia?

No

Yes

$$
1 \text { (reference) }
$$$$
1.194(0.962,1.480)
$$$$
0.988(0.975,1.000)
$$$$
0.952(0.937,0.967)
$$

1 (reference)

$0.625(0.423,0.923)$

$1.012(0.997,1.027)$

$0.952(0.927,0.977)$

$$
\begin{array}{cc}
1 \text { (reference) } & 1 \text { (reference) } \\
0.678(0.552,0.834) & 0.761(0.551,1.052) \\
0.892(0.704,1.131) & 0.751(0.515,1.094)
\end{array}
$$

$\begin{array}{cc}1 \text { (reference) } & 1 \text { (reference) } \\ 0.897(0.772,1.001) & 0.878(0.726,1.061)\end{array}$

1 (reference)

1 (reference) $1.035(0.874,1.226) \quad 1.326(1.000,1.760)$

$0.948(0.819,1.098) \quad 1.390(1.044,1.850)$

$\begin{array}{cc}1 \text { (reference) } & 1 \text { (reference) } \\ 1.096(0.934,1.285) & 1.650(0.960,1.415)\end{array}$

3.1 Comparative analysis birth length status data by regions in Ghana

In this section we considered comparative analysis of the birth length status data by regions. This means that we fitted logistic regression models to data for each regions and best model selected by fitting the four models in Section 3.2 above. The best model is selected using their respective AICs and BICs, where the model with the lowest AIC or BIC is the best fitting model for the data. The results, by region, are presented in Table 6 .

It can be observed that knowledge about ovulation cycle is a significant predictor of birth length status in Ashanti, Northern, and Volta regions. For Ashanti and Northern regions, wives who have 
knowledge about their ovulation are less likely to give birth to their first child after 10 months of marriage. However, for those in Volta region, those with knowledge about their ovulation cycle are more likely to give birth to their first child after 10 months of marriage. The results also suggest that wives who reported that beating is justified if she neglects child are less likely to give birth to their first child after 10 months of marriage in Ashanti, Volta, and Western Regions. This predictor leads to increase in the likelihood of giving birth to first child 10 months after marriage in Eastern, Northern, and Greater Accra Regions. However this increase is not statistically significant. Primary education increases the likelihood of giving birth after 10 months of marriage in the Ashanti, Eastern, and Western Regions and Secondary education increases the likelihood of giving birth after 10 months in Volta Regio.

We observed that beating is justified if goes out without husband's notice significantly predicts birth length status in Ashanti, Eastern, and Western Regions, with increase likelihood of giving birth after 10 months in the Western Regions. Also, wives who have ever terminated pregnancy are more likelihood to give birth after 10 months of marriage in Centeral and Uppr Weste Regions. Wives who are Moslem are more likely to give birth within 10 months of marriage in Brong Ahafo Region and wives who reported that beating is justified if she burns food are less likely to give birth after 10 months of marriage in the Brong Ahafo Region. For every unit increase in weight, there is 0.013 in the likelihood of giving birth after 10 months in Eastern Region. Wives who reported that they have Akan ethnitic background are less likely to give birth after 10 months in Brong Ahafo, Central, Western, and Greater Accra Regions.

A unit increase in the age decreases the likelihood of giving birth after 10 months of marriage in the Brong Ahafo and Northern, and increases the likelihood in Volta and Western Regions. The results showed that those who are in middle income class are more likely to give birth after 10 months of marriage in the Central, Northern, and Volta Regions. A unit increase in wive's hemoglobin level, 
increases the likelihood of giving birth after 10 months in the Eastern, Upper East, and Upper West Regions and a decrease in the Central Region. Wives who reported that beating is justified if she refuses sex are more likely to give birth after 10 months of marriage in the Central and Upper West Regions. Beating justified if argues with husband decreases the chance of giving birth after 10 months of marriage in Central and Upper East Regions and increases the likelihood in the Eastern Region.

We found that higher education reduces the risk of giving birth after 10 months of marriage in the Central, Upper West, and Western Regions and increases the risk in Volta and Greater Accra Regions. Wives in the Upper East and Volta Regions who have ever used contraceptives are more likely to give birth within 10 months of marriage and those in the Eastern and Greater Accra Regions are more likely to give birth after 10 months of marriage. This gives an indication that those in Volta region ovulation cycle might have been affected by the use contraceptive, hence leading to unplan pregnancy since their knowledge on ovulation cycle increases their likelihood of giving birth to their first child after 10 or marriage. Wives with Anaemia have increased risk of giving birth after 10 months of marriage in Eastern, Upper West, and Volta Regions with a reduced risk in the Greater Accra Region. BMI reduces the chance of giving birth after 10 months of marriage among wives in the Eastern Region and a unit increase in the age at first sex at first cohabition decreases the likelihood of giving birth after 10 months of marriage among wives in the Northern, Upper West, Volta, and Greater Accra Regions. In the Upper West Region, wives who are Christian have higher risk of giving birth after 10 months of marriage and reduced risk in Northern, Upper East, and Volta Regions. In Western Region, wives are classified as rich income class are more likely to give birth after 10 months of marriage. Beating is justified if wife burns food decreases the likelihood of giving to first child after 10 months of marriage in the Ashanti Region. 
Table 5: Comparative analysis of predictors of birth length status by region in Ghana using logis

\begin{tabular}{|c|c|c|c|c|c|c|c|c|}
\hline \multirow[b]{2}{*}{ Predictors } & \multicolumn{8}{|l|}{ Regions } \\
\hline & Ashanti & $\begin{array}{l}\text { Brong } \\
\text { Ahafo }\end{array}$ & Central & Eastern & Northern & $\begin{array}{l}\text { Upper } \\
\text { East }\end{array}$ & $\begin{array}{l}\text { Upper } \\
\text { West }\end{array}$ & Volt \\
\hline $\begin{array}{l}\text { Knowledge of } \\
\text { ovulution }\end{array}$ & $\begin{array}{l}\mathrm{OR}=0.28 \\
5 \\
, \mathrm{p} \text {-value }= \\
0.001\end{array}$ & & & & $\begin{array}{l}\mathrm{OR}=0.5 \\
24 \\
, \mathrm{p} \text {-value }= \\
0.012\end{array}$ & & & $\begin{array}{l}\mathrm{OR}= \\
27 \\
\mathrm{p}-\mathrm{v} \\
0.00\end{array}$ \\
\hline $\begin{array}{l}\text { Beating } \\
\text { justified if } \\
\text { neglects child }\end{array}$ & $\begin{array}{l}\mathrm{OR}=0.166, \\
\text { p-value }= \\
0.002\end{array}$ & & & $\begin{array}{l}\mathrm{OR}= \\
4.310, \mathrm{p}- \\
\text { value }= \\
0.070\end{array}$ & $\begin{array}{l}\mathrm{OR}= \\
1.595, \mathrm{p}- \\
\text { value }= \\
0.064\end{array}$ & & & $\begin{array}{l}\mathrm{OR}= \\
0.12 \\
\text { valu } \\
0.00\end{array}$ \\
\hline $\begin{array}{l}\text { Primary } \\
\text { education }\end{array}$ & $\begin{array}{l}\mathrm{OR}=3.370, \\
\mathrm{p} \text {-value }= \\
0.133\end{array}$ & & & $\begin{array}{l}\mathrm{OR}= \\
5.109, \mathrm{p}- \\
\text { value }= \\
0.009\end{array}$ & & & & \\
\hline $\begin{array}{l}\text { Secondary } \\
\text { education }\end{array}$ & $\begin{array}{l}\text { OR }=0.707, \\
\text { p-value }= \\
0.380\end{array}$ & & & & & & $\begin{array}{l}\mathrm{OR}= \\
0.764, \mathrm{p}- \\
\text { value }= \\
0.186\end{array}$ & \\
\hline $\begin{array}{l}\text { At least one } \\
\text { wife }\end{array}$ & $\begin{array}{l}\text { OR }=0.260, \\
\text { p-value }= \\
0.022\end{array}$ & & & & & & & \\
\hline $\begin{array}{l}\text { Beating } \\
\text { justified if goes } \\
\text { out without }\end{array}$ & $\begin{array}{l}\text { OR }=5.523, \\
\text { p-value }\end{array}$ & & & $\begin{array}{l}\mathrm{OR}= \\
0.094, \mathrm{p}- \\
\text { value }=\end{array}$ & & & & $\begin{array}{l}\text { OR } \\
5.51 \\
\text { valu }\end{array}$ \\
\hline
\end{tabular}




\begin{tabular}{|c|c|c|c|c|c|c|c|}
\hline $\begin{array}{l}\text { husband's } \\
\text { notice. }\end{array}$ & $=0.020$ & & & 0.002 & & & 0.05 \\
\hline $\begin{array}{l}\text { Ever } \\
\text { terminated } \\
\text { pregnancy }\end{array}$ & $\begin{array}{l}\mathrm{OR}=0.583, \\
\text { p-value }= \\
0.120\end{array}$ & & $\begin{array}{l}\mathrm{OR}= \\
4.067, \mathrm{p}- \\
\text { value }= \\
0.015\end{array}$ & & & $\begin{array}{l}\mathrm{OR}= \\
3.274, \mathrm{p}- \\
\text { value }= \\
0.011\end{array}$ & \\
\hline Islamic & $\begin{array}{l}\mathrm{OR}=1.815, \\
\mathrm{p}-\mathrm{value}= \\
0.202\end{array}$ & $\begin{array}{l}\mathrm{OR}= \\
0.404, \\
\text { p-value } \\
= \\
0.031\end{array}$ & & & & & $\begin{array}{l}\mathrm{OR}= \\
0.05 \\
\text { valu } \\
0.11\end{array}$ \\
\hline $\begin{array}{l}\text { Beating } \\
\text { justified if } \\
\text { burns food }\end{array}$ & & $\begin{array}{l}\mathrm{OR}= \\
0.198 \\
\text { p-value } \\
= \\
0.004\end{array}$ & & & & & \\
\hline Weight & & $\begin{array}{l}\text { OR }= \\
0.997 \\
\text { p-value } \\
= \\
0.104\end{array}$ & & $\begin{array}{l}\mathrm{OR}= \\
1.013, \mathrm{p}- \\
\text { value }= \\
0.011\end{array}$ & & & $\begin{array}{l}\mathrm{OR}= \\
0.99 \\
\text { valu } \\
0.17\end{array}$ \\
\hline Akan & & $\begin{array}{l}\mathrm{OR}= \\
0.448, \\
\mathrm{p} \text {-value } \\
= \\
0.021\end{array}$ & $\begin{array}{l}\mathrm{OR}= \\
0.191, \mathrm{p}- \\
\text { value }= \\
0.038\end{array}$ & & & & \\
\hline Age & & $\begin{array}{l}\mathrm{OR}= \\
0.958\end{array}$ & & & $\begin{array}{l}\mathrm{OR}= \\
0.959, \mathrm{p}-\end{array}$ & & $\begin{array}{l}\text { OR } \\
1.13\end{array}$ \\
\hline
\end{tabular}




\begin{tabular}{|c|c|c|c|c|c|c|c|}
\hline & $\begin{array}{l}\mathrm{p} \text {-value } \\
= \\
0.088\end{array}$ & & & $\begin{array}{l}\text { value }= \\
0.022\end{array}$ & & & $\begin{array}{l}\text { valu } \\
0.00\end{array}$ \\
\hline Midel income & $\begin{array}{l}\mathrm{OR}= \\
1.960, \\
\text { p-value } \\
= \\
0.129\end{array}$ & & & $\begin{array}{l}\mathrm{OR}= \\
5.573, \mathrm{p}- \\
\text { value }= \\
0.099\end{array}$ & & & $\begin{array}{l}\mathrm{OR}= \\
5.52 \\
\text { valu } \\
0.00\end{array}$ \\
\hline $\begin{array}{l}\text { Haemoglobin } \\
\text { level }\end{array}$ & & $\begin{array}{l}\mathrm{OR}=0.962, \\
\mathrm{p}-\mathrm{value}= \\
0.001\end{array}$ & $\begin{array}{l}\mathrm{OR}=1.093, \\
\mathrm{p} \text {-value }= \\
0.001\end{array}$ & & $\begin{array}{l}\mathrm{OR}=1.022, \\
\mathrm{p} \text {-value }= \\
0.067\end{array}$ & $\begin{array}{l}\mathrm{OR}=1.051, \\
\mathrm{p}-\mathrm{value}= \\
0.031\end{array}$ & \\
\hline $\begin{array}{l}\text { Beating } \\
\text { justified if } \\
\text { refuses sex }\end{array}$ & & $\begin{array}{l}\mathrm{OR}=6.869, \\
\mathrm{p}-\mathrm{value}= \\
0.014\end{array}$ & & & & $\begin{array}{l}\mathrm{OR}=3.013, \\
\mathrm{p} \text {-value }= \\
0.053\end{array}$ & \\
\hline $\begin{array}{l}\text { Beating } \\
\text { justified if } \\
\text { argues with } \\
\text { husband }\end{array}$ & & $\begin{array}{l}\mathrm{OR}=0.293, \\
\text { p-value }= \\
0.038\end{array}$ & $\begin{array}{l}\text { OR=8.585, } \\
\text { p-value }= \\
0.019\end{array}$ & & $\begin{array}{l}\mathrm{OR}=0.162, \\
\mathrm{p} \text {-value }= \\
0.037\end{array}$ & & \\
\hline $\begin{array}{l}\text { Higher } \\
\text { education }\end{array}$ & & $\begin{array}{l}\mathrm{OR}=0.678, \\
\text { p-value }= \\
0.005\end{array}$ & & & & $\begin{array}{l}\mathrm{OR}=0.456, \\
\mathrm{p} \text {-value }= \\
0.001\end{array}$ & $\begin{array}{l}\mathrm{OR}= \\
\mathrm{p}-\mathrm{va} \\
0.08\end{array}$ \\
\hline $\begin{array}{l}\text { Ever used } \\
\text { contraceptive }\end{array}$ & & & $\begin{array}{l}\mathrm{OR}=4.773, \\
\mathrm{p} \text {-value }= \\
0.001\end{array}$ & & $\begin{array}{l}\mathrm{OR}=0.522, \\
\mathrm{p} \text {-value }= \\
0.056\end{array}$ & & $\begin{array}{l}\mathrm{OR}= \\
\mathrm{p}-\mathrm{va} \\
0.00\end{array}$ \\
\hline Anaemia & & & $\begin{array}{l}\mathrm{OR}=4.586, \\
\text { p-value }= \\
0.017\end{array}$ & & & $\begin{array}{l}\mathrm{OR}=5.772, \\
\mathrm{p} \text {-value }= \\
0.007\end{array}$ & $\begin{array}{l}\text { OR= } \\
\text { p-va } \\
0.05\end{array}$ \\
\hline
\end{tabular}




\begin{tabular}{|c|c|c|c|c|}
\hline BMI & $\begin{array}{l}\mathrm{OR}=0.997, \\
\mathrm{p}-\mathrm{value}= \\
0.038\end{array}$ & & & $\begin{array}{l}\text { OR=0.999, } \\
\text { p-value = } \\
0.094\end{array}$ \\
\hline $\begin{array}{l}\text { Age at first sex } \\
\text { at first } \\
\text { cohabition }\end{array}$ & & $\begin{array}{l}\text { OR=0.931, } \\
\text { p-value = } \\
0.057\end{array}$ & & $\begin{array}{l}\text { OR=0.931, } \\
\text { p-value }= \\
0.148\end{array}$ \\
\hline Christianity & & $\begin{array}{l}\mathrm{OR}=0.628, \\
\mathrm{p} \text {-value }= \\
0.076\end{array}$ & $\begin{array}{l}\mathrm{OR}=0.662, \\
\mathrm{p} \text {-value }= \\
0.195\end{array}$ & $\begin{array}{l}\mathrm{OR}=2.192, \\
\mathrm{p} \text {-value }= \\
0.033\end{array}$ \\
\hline Rich income & & & & \\
\hline
\end{tabular}




\section{Discussion and Conclusion}

In this paper, we investigated the effects of various risk factors on first child's birth length after marriage. Birth length in this study is a dichotomous variable coded as 1 if an individual gives birth to her first child after 10 months of marriage and 0 if an individual gives birth to her first child within 10 months of marriage. The study used birth records data from the 2014 Ghana Demographic and Health Survey (2014GDHS). Some of the variables have missing values [17], [18], [39]-[41] and hence excluded from the analyses. This means that the analyses in this paper are restricted to 5,004 complete cases [18], [41] individuals with no missing values with 30 risk factors of birth length status.

We assessed the effects of the various risk factors on the status of the dichotomous birth length variable using a logistic regression model [23], [24], [42]. The purpose of this exercise is to identify best risk factors (predictors) of birth length status. We built our regression model for the dichotomous birth length variable by fitting four logistic regression Models A, B, C, and D (explained in Section 3). Results from these models were compared, using their respective Akaike Information Criterion (AIC), and best fitting model for the data selected. The AIC is an estimator which measures the relative quality of statistical models for a given set of data. The Model D was selected as the besting fitting model since it has the lowest AIC and Bayesian Information Criterion (BIC) as well as parsimonious (smallest number of parameters/variables). We then assessed the predictive power of the Model D in predicting the probabilities of the status of birth length. We achieved this using the Receiver Operating Characteristic (ROC) curve. The ROC curve is a plot of sensitivity versus 1 -specificity. With an optimal cuttoff value of 0.63 , the Model D produces a higher sensitivity relative specificity, and specificity (the probability that an individual gives birth to first child within 10 months of marriage given that such individual actually gives birth within 10 months) is $36.69 \%$. The probability of 
misclassifications for positive and negative rates are $27.39 \%$ and $56.66 \%$ respectively. So with the ROC curve, when sensitivity $=1$-specificity, the model has no predictive power (and area under the curve is $50 \%$ ). The ROC curve in this study gives an indication that the area under the curve is approximately 64\%, which indicates that the Model Dhas higher predictive power.

The results from Model D showed that wives whose husbands have higher education are less likely to give birth to their first child after 10 months of marriage. It was observed that women who reported that beating is justified if she goes out without her husband's notice are more likely to give birth to their first child after 10 months of marriage. This suggests that wives are more likely to violate this order and hence there may have frequent misunderstanding between partners. This will subsequently lead to infrequent sexual intercourse which may delay conception among such women. On the other hand, we found that among wives who reported that beating is justified if she neglects child are more likely to give birth to their first child within 10 months of marriage. This finding suggests that wives who believe that husbands care much about their children are more willing to give first within the shortest possible time. Wives who reported that beating is justified when she argues with her husband are less likely to give birth to their first child after 10 months of marriage. Th finding suggests that such wives are more likely to offer sex to their husband without arguing/refusing anytime they demand, and hence more likely to conceive within 1 month after marriage. These findings, overall, appear to give an indication that various forms of social violence are key factors in determining how long a woman stays in a marriage before giving birth to the first child and, possibly, the next child and so on.

The results in this study also showed that there is increase in the likelihood of giving birth to the first child after 10 months of marriage for every unit increase in the age of respondent at marriage. This 
could be explained by the higher proportion of contraceptive use among older age ( $>18$ years) wives relative to a lower contraceptive use among the younger age $(\leq 18)$ age wives. Also, for every unit increase in the age of respondent at first sex, there is a decrease in the likelihood of giving birth to the first child after 10 months in marriage, which appears to suggest that if a woman stays longer to have her first sex, then such woman is more likely to have more sex in marriage and more likely to conceive within 1 month of marriage. Though not general, but it is more likely that younger wives and those who stay longer to have their first sex may be more willing or may have much desire to have sex, hence more likely to conceive with 1 month of the marriage.

Our study results suggest that for conception within 1 month of marriage or to give birth to first child within 10 months of marriage, wives and husbands should have frequent sex. The results also appear to suggest that any negative social behaviour or policies, on the part of the husband or society, that will reduce the likelihood of having frequent sex with the wife must be discouraged. Women who use contraceptives should always seek advise from professional since the use can reduce their chances of conception and child birth ultimately. Women who wish to have children are encouraged to desist from termination of pregnancy at any time of their life since this act has the likelihood of reducing chances of conception for such women. Based on our results, we also encourage husbands to openly express their desire and love for their children since this increases the likelihood of wives desire to give birth. This leads to frequent sex, which then reduces conception time, and hence, child birth within the shortest possible time.

\section{Declarations:}

\section{Funding}

The study receives no funding. 


\section{Availability of data and materials}

The authors do not have the ability to make data available.

\section{Competing interests}

The authors declare that he has no competing interest.

\section{Consent to publish}

Not applicable.

\section{Ethics approval (and consent to participate)}

Not applicable.

\section{Authors' contributions}

AI carried out the literature review, statistical analyses, interpretation of results, and wrote the manuscript. All authors contributed to the interpretation and reviewing or proof-reading of the manuscript. All authors have read and approved the final version of the manuscript.

\section{References}

[1] K. Hammarberg, J. R. W. Fisher, and K. H. Wynter, "Psychological and social aspects of pregnancy, childbirth and early parenting after assisted conception: A systematic review," Human Reproduction Update. 2008, doi: 10.1093/humupd/dmn030.

[2] A. L. Greil, "Infertility and psychological distress: A critical review of the literature," Soc. Sci. Med., 1997, doi: 10.1016/S0277-9536(97)00102-0.

[3] A. Eugster and A. J. J. M. Vingerhoets, "Psychological aspects of in vitro fertilization: A review," Social Science and Medicine. 1999, doi: 10.1016/S0277-9536(98)00386-4.

[4] C. M. Verhaak, J. M. J. Smeenk, A. W. M. Evers, J. A. M. Kremer, F. W. Kraaimaat, and D. D. M. Braat, "Women's emotional adjustment to IVF: A systematic review of 25 years of research," Human Reproduction Update. 2007, doi: 10.1093/humupd/dml040.

[5] M. Sandelowski, B. G. Harris, and D. Holditch-Davis, "Pregnant moments: The process of conception in infertile couples," Res. Nurs. Health, 1990, doi: 10.1002/nur.4770130503.

[6] R. M. DUNNINGTON and G. GLAZER, "Maternal Identity and Early Mothering Behavior in Previously Infertile and Never Infertile Women," J. Obstet. Gynecol. Neonatal Nurs., 1991, doi: 10.1111/j.1552-6909.1991.tb01694.x.

[7] P. M. Jones and L. T. Olsan, "Performative Rituals for Conception and Childbirth in England, 900-1500," Bull. Hist. Med., 2015, doi: 10.1353/bhm.2015.0076.

[8] N. Y. Osei, "Need for accessible infertility care in Ghana: the patients' voice.," Facts, views Vis. ObGyn, 2016.

[9] L. James-Hawkins, C. Peters, K. VanderEnde, L. Bardin, and K. M. Yount, "Women's agency and its relationship to current contraceptive use in lower- and middle-income countries: A systematic review of the literature," Glob. Public Health, 2018, doi: 10.1080/17441692.2016.1239270.

[10] U. D. Upadhyay et al., "Women's empowerment and fertility: A review of the literature," Social Science and Medicine. 2014, doi: 10.1016/j.socscimed.2014.06.014. 
[11] N. Prata, P. Tavrow, and U. Upadhyay, "Women's empowerment related to pregnancy and childbirth: introduction to special issue," BMC Pregnancy Childbirth, 2017, doi: 10.1186/s12884-017-1490-6.

[12] J. Cong, P. Li, L. Zheng, and J. T. Tan, "Prevalence and risk factors of infertility at a rural site of Northern China," PLoS One, 2016, doi: 10.1371/journal.pone.0155563.

[13] R. Sharma, K. R. Biedenharn, J. M. Fedor, and A. Agarwal, "Lifestyle factors and reproductive health: Taking control of your fertility," Reproductive Biology and Endocrinology. 2013, doi: 10.1186/1477-7827-11-66.

[14] N. J. Parr, "CHANGES IN THE FACTORS AFFECTING FERTILITY IN GHANA DURING THE EARLY STAGES OF THE FERTILITY DECLINE,” Source: Genus, 1998.

[15] I. Abdul-Karim and F. Gumedze, "Sensitivity analysis for the generalized shared-parameter model framework,” J. Biopharm. Stat., pp. 1-19, 2019.

[16] I. Abdul-Karim and F. Gumedze, "Application of sensitivity analysis to incomplete longitudinal CD4 count data,” J. Appl. Stat., pp. 1-16, 2018.

[17] I. Abdul-Karim and F. Gumedze, "An application of a pattern-mixture model with multiple imputation for the analysis of longitudinal trials with protocol deviations," BMC Med. Res. Methodol., 2019, doi: 10.1186/s12874-018-0639-y.

[18] G. Molenberghs, G. Fitzmaurice, M. Kenward, B. Tsiatis, and G. Verbeke, Handbook of missing data methodology. 2014.

[19] M. K. Cowles, "Modelling survival data in medical research," J. Am. Stat. Assoc., vol. 99, no. 467, pp. 905-907, 2004.

[20] D. R. Cox, "Regression models and life-tables," in Breakthroughs in statistics, Springer, 1992, pp. 527-541.

[21] E. R. Ziegel and S. Menard, “Applied Logistic Regression Analysis,” Technometrics, 1996, doi: $10.2307 / 1270433$.

[22] E. L. Spitznagel, “6 Logistic Regression,” Handbook of Statistics. 2007, doi: 10.1016/S01697161(07)27006-3.

[23] D. W. Hosmer and S. Lemeshow, Applied Logistic Regression ( 2nd ed. ). 2002.

[24] P. D. Allison, Logistic Regression Using SAS: Theory and Application. 2012.

[25] I. Abdul-Karim, D. Otoo, and B. Mahama, "Investigating the Determinants of Maternal Care Services Utilization in the Brong Ahafo Region of Ghana," Open J. Stat., 2019, doi: 10.4236/ojs.2019.93022.

[26] S. Menard, Applied logistic regression analysis, vol. 106. Sage, 2002.

[27] D. W. Hosmer Jr, S. Lemeshow, and R. X. Sturdivant, Applied logistic regression, vol. 398. John Wiley \& Sons, 2013.

[28] I. Abdul-Karim, K. Opoku-Ameyaw, F. K. Bukari, B. Mahama, and J. J. A. Akooti, "HIV Testing Decision and Determining Factors in Ghana," World J. AIDS, vol. 9, no. 2, pp. 85-104, 2019.

[29] I. Abdul-Karim, O. Dominic, and M. Bashiru, "Investigating the determinants of maternal care services utilization in the Brong Ahafo region of Ghana," Open J. Stat., vol. 9, no. 3, pp. 927940, 2019.

[30] I. Abdul-Karim, F. K. Bukari, K. Opoku-Ameyaw, G. O. Afriyie, and K. Tawiah, "Factors That Determine the Likelihood of Giving Birth to the First Child within 10 Months after Marriage," J. Pregnancy, vol. 2020, 2020.

[31] A. K. Iddrisu, K. Tawiah, F. K. Bukari, and W. Kumi, "Frequentist and Bayesian Regression Approaches for Determining Risk Factors of Child Mortality in Ghana," Biomed Res. Int., 2020, doi: 10.1155/2020/8168479.

[32] D. Collett, "Modelling survival data," in Modelling Survival Data in Medical Research, 
Springer, 1994, pp. 53-106.

[33] G. van Belle, L. D. Fisher, P. J. Heagerty, and T. Lumley, "A Methodology for the Health Sciences." John Wiley \& Son, Inc, 2004.

[34] D. J. Hand and D. Collett, "Modelling Binary Data.," Appl. Stat., 2006, doi: 10.2307/2986244.

[35] R. Kumar and A. Indrayan, "Receiver operating characteristic (ROC) curve for medical researchers.," Indian Pediatr., 2011.

[36] L. Gonçalves, A. Subtil, M. Rosário Oliveira, and P. De Zea Bermudez, "ROC curve estimation: An overview," Revstat Stat. J., 2014.

[37] StataCorp, Stata: Release 13. Statistical Software. 2013.

[38] StataCorp, "Stata Statistical Software: Release 15.1. College Station, TX: StataCorp LP.," 2015. 2015, doi: $10.2307 / 2234838$.

[39] L. Thabane et al., "A tutorial on sensitivity analyses in clinical trials: The what, why, when and how," BMC Medical Research Methodology. 2013, doi: 10.1186/1471-2288-13-92.

[40] Committee for Medicinal Products for Human Use (CHMP) and R. J. A. Little, "Guideline on missing data in confirmatory clinical trials," London Eur. Med. ..., 2011, doi: 10.2307/2290157.

[41] I. Abdul-Karim and F. Gumedze, "Application of sensitivity analysis to incomplete longitudinal CD4 count data,” J. Appl. Stat., 2019, doi: 10.1080/02664763.2018.1510476.

[42] A. J. Scott, D. W. Hosmer, and S. Lemeshow, "Applied Logistic Regression.," Biometrics, 2006, doi: $10.2307 / 2532419$. 